\title{
The association between concealing emotions at work and medical utilization in Korea
}

\author{
Hongdeok Seok ${ }^{1,2}$, Jin-Ha Yoon ${ }^{1,2,3}$, Wanhyung Lee ${ }^{1,2}$, June-Hee Lee ${ }^{1,2}$, Pil Kyun Jung ${ }^{1,2}$, Inah Kim ${ }^{1,2}$, \\ Jong-Uk Won ${ }^{1,2,3}$ and Jaehoon Roh ${ }^{1,2,3^{*}}$
}

\begin{abstract}
Objectives: We aimed to investigate the association between concealing emotions at work and medical utilization.

Methods: Data from the 2007-2009 4th Korea National Health and Nutrition Examination Survey (KNHANES IV) was used, 7,094 participants (3,837 males, 3,257 females) aged between 20 and 54 who were economically active and completed all necessary questionnaire items were included. Odds ratios (ORs) and 95\% confidence intervals ( $95 \%$ Cl) for differences in hospitalization, outpatient visits, and pharmaceutical drug use between those who concealed their emotions and those who did not were investigated using logistic regression models with and without gender stratification.
\end{abstract}

Results: Among those who concealed their emotions $(n=2,763), 47.4 \%$ were females, and $50.1 \%$ had chronic disease. In addition, 9.7\% of the concealing emotions group had been hospitalized within the last year, $24.8 \%$ had been outpatients in the last two weeks, and $28.3 \%$ had used pharmaceutical drugs in the last two weeks. All ORs represent the odds of belonging to the concealing emotions group over the non-concealing emotions group. After adjustment for individual, occupational, socioeconomic and disease factors, the adjusted ORs (95\% Cl) in hospitalization are $1.29(1.08 \sim 1.53)$ in the total population, $1.25(0.98 \sim 1.60)$ in males and $1.30(1.02 \sim 1.66)$ in females, in outpatient visits are $1.15(1.02 \sim 1.29)$ in the total population, $1.05(0.88 \sim 1.24)$ in males and 1.25 $(1.06 \sim 1.47)$ in females and in pharmaceutical drug use are $1.12(1.01 \sim 1.25)$ in the total population, 1.08 $(0.92 \sim 1.27)$ in males and $1.14(0.98 \sim 1.33)$ in females.

Conclusions: Those who concealed their emotions at work were more likely to use medical services. Moreover, the health effects of concealing emotions at work might be more detrimental in women than in men.

Keywords: Occupational health, Psychological stress, Korea, Health services accessibility, Inpatients, Outpatients, Pharmacy

\section{Introduction}

Concealing emotions at work is an important requirement of certain types of emotional labor, which leads to occupational stress [1]. Concealing emotions influences the occurrence of various adverse health effects, such as cardiovascular disease and cancer, and also increases mortality [2]. The act of concealing emotions consists of both repression and suppression. Repression refers to the subconscious concealment of emotions, whereas suppression refers to the conscious concealment of emotions [3].

\footnotetext{
* Correspondence: jhroh@yuhs.ac

${ }^{1}$ Graduate School of Public Health, Yonsei University, Seoul, Korea

${ }^{2}$ The Institute for Occupational Health, Yonsei University College of Medicine, Seoul, Korea

Full list of author information is available at the end of the article
}

The prevalence of occupational stress related to emotional disturbance such as concealing emotions and its health effects (e.g., burnout) is increasing worldwide [4].

Occupational stress is linked to various chronic and acute diseases, such as cardiovascular disease [5]. Furthermore, occupational stress induces long absences due to sickness [6]. Hence, it is plausible that concealing emotions at work is linked to human health. Although previous studies have investigated the detrimental effects on health from concealing emotions at work, to the best of our knowledge, the association between concealing emotions at work and medical utilization has not yet been investigated.

The investigation of medical utilization is a widely used method for measuring health effects, and can be 
assessed through several indicators including the number of hospitalizations, outpatient visits, emergency department visits, and frequency of pharmaceutical drug use [7]. The following four subsets of factors have been found to affect medical utilization, namely, individual factors such as gender [8-10], age $[8,10]$, smoking [11], alcohol intake $[11,12]$, and body mass index (BMI) $[7,11,13]$; occupational factors such as employment status [14] and shift work [15]; socioeconomic factors such as marriage [14], region [16], income [8], education [8], type of public insurance and having additional private insurance [14,17-19]; and individual disease factors such as chronic disease status [8]. Thus, when investigating the effects of concealing emotions at work on increased medical utilization, we should consider controlling for individual, occupational, socioeconomic, and individual disease factors. However, no previous in-depth analyses were found in the literature.

Some reports have suggested that medical utilization differs between men and women [8-10]. Thus, a genderstratified analysis is required to elucidate the association between concealing emotions at work and medical utilization. We aimed to investigate the association between concealing emotions at work and medical utilization using a multivariate logistic regression model that incorporated individual factors, occupational factors, socioeconomic status, and individual disease factors. Furthermore, we conducted a gender-stratified analysis to investigate gender effects.

\section{Materials and methods Study design}

Data from the 4th Korea National Health and Nutrition Examination Survey (KNHANES IV), collected between 2007 and 2009, were used for all data analyses in this study. Participation in the KNHANES IV was voluntary. All participants provided written informed consent and the Institutional Review Board of the Korea Centers for Disease Control and Prevention approved this study (No. 2007-02CON-04-P, 2008-04-EXP-01-C, 2009-01-CON-03-2C).

The KNHANES IV was a nationwide cross-sectional study conducted by the Korean Ministry of Health and Welfare. Households were randomly selected for participation using stratified multistage probability sampling based on geographical areas of the Korean population. A total of 600 geographical sampling units were used in the KNHANES IV, which generated a sample of 13,800 households for data collection.

\section{Participants}

In total, 24,871 participants from three years of KNHANES IV data (2007-2009) were considered for enrollment in this study $(2007=4,594,2008=9,744,2009=10,533)$. Of these, 10,031 economically active participants who completed the questionnaire item on concealing emotions at work were selected. Next, we excluded participants older than 54 and younger than 20 , because the average retirement age in Korea is 55 and those younger than 20 were not considered economically active [20]. Thus, 7,094 participants were included, but there were missing values for medical utilization: 6 for hospitalization, 3 for outpatient visits, and 1 for pharmaceutical drug use. Thus, there were 7,088 participants for hospitalization (3,834 males, 3,254 females), 7,091 participants for outpatient visits $(3,835$ males, 3,256 females), and 7,093 participants for pharmaceutical drug use (3,836 males, 3,257 females) included in the final analyses.

\section{Concealing emotions at work}

We used a questionnaire item that asked, "Are you concealing emotions at work?" in order to group participants by whether or not they hide their emotions at work. In response to this question, participants answered 1 =never, 2 =rarely, 3 =sometimes, $4=$ always . The concealing emotions group included all participants who answered 3 or 4, whereas the non-concealing emotions group included all participants who answered 1 or 2 .

\section{Medical utilization}

We used three yes/no questionnaire items to assess medical utilization: "Have you been hospitalized in the past year?", "Have you had an outpatient visits within the last two weeks?", and "Have you used pharmacy drugs over the last two weeks?"

\section{Covariates}

Individual factors were age, smoking, alcohol consumption, and obesity. The smoking group included current smokers, whereas the non-smoking group included those who had never smoked or past smokers. Heavy drinkers were those who consumed an average of $\geq 7$ units of alcohol for men and $\geq 5$ units for women $\geq 2$ days/week. Moderate drinkers included those who consumed more than one glass of alcohol per month over the past year, and non-drinkers included those who never drink or drank less than one glass of alcohol per month over the past year. BMI was categorized into three groups as low weight $\left(\mathrm{BMI}<18.5 \mathrm{~kg} / \mathrm{m}^{2}\right)$, normal weight (BMI $18.5-25 \mathrm{~kg} / \mathrm{m}^{2}$ ), and obese (BMI $\left.>25 \mathrm{~kg} / \mathrm{m}^{2}\right)$.

Occupational factors included employment status (selfemployed or paid worker) and work schedule (shift worker or day worker).

Socioeconomic factors included marital status, region, income, education, type of public insurance and having additional private insurance. Marriage was divided as either married/divorced or never married. Region was dichotomized as urban or rural. Household income was estimated using the quadrants provided by the KNHANES and relabeled as high and low, which includes the top two 
and bottom two quadrants, respectively. Education was divided among those who only completed middle school or less, those who only graduated from high school or completed some high school, and those who attended college or higher. For classifying public insurance, participants had national health insurance, national medical protection, or none of the above. Additional private insurance was recorded as yes or no.

For disease factors, participants were classified according to chronic disease status (yes or no). We used data on suffering from illness. The KNHANES survey included a question asking "Do you have this disease now?" for the following 40 diseases: hypertension, hyperlipidemia, stroke, myocardial infarction, angina pectoris, hemorrhoids, osteoarthritis, rheumatic arthritis, osteoporosis, lower back pain, pulmonary tuberculosis, non-pulmonary tuberculosis, asthma, chronic obstructive pulmonary disease, sinusitis, bronchiectasis, allergic rhinitis, depression, anemia, atopic dermatitis, chronic renal failure, incontinence, temporomandibular joint disease, diabetic mellitus, thyroid disease, cataract, glaucoma, otitis media, gastric cancer, hepatic cancer, colon cancer, breast cancer, cervical cancer, lung cancer, other cancer group 1, other cancer group 2, gastroduodenal ulcer, chronic hepatitis $\mathrm{B}$, chronic hepatitis $\mathrm{C}$, and liver cirrhosis. We dichotomized chronic disease status, those who answered "Yes" to one or more of the chronic diseases were the chronic disease group, and those who answered "No" to all were the non-chronic disease group.

\section{Statistical analysis}

Chi-squared tests were used to identify differences between those who concealed and did not conceal their emotions for general characteristics as well as hospitalization, outpatient visits, and pharmaceutical drug use.

We also conducted a chi-squared test between the hospitalization and non-hospitalization groups, between outpatient and non-outpatient visits groups, and between pharmaceutical drug use and non-pharmaceutical drug use groups in the same way.

We calculated odds ratios (ORs) and 95\% confidence intervals (95\% CI) for differences in hospitalization, outpatient visits, and pharmaceutical drug use between those who concealed and did not conceal their emotions using logistic regression models for the total population and for men and women separately.

SAS 9.2 (SAS, Inc., Cary, NC, USA) was used for all statistical analyses and a p-value $<0.05$ was considered significant.

\section{Results}

\section{Concealing emotions at work}

Table 1 presents the differences between groups, in addition to significance values. 2,763 participants were concealing emotions group, whereas 4,331 participants were non-concealing emotions group. In the concealing emotions group, $47.4 \%$ were females, $67.7 \%$ were $30-49$ years old, $18.0 \%$ were heavy drinkers, $31.7 \%$ were smokers, $31.6 \%$ were obese, $65.1 \%$ were paid workers, and $22.3 \%$ were shift workers, whereas only $17.8 \%$ of the non-concealing emotions group were shift workers (p-value $<0.001$ ). Furthermore, $81.6 \%$ of the concealing emotions group were married, and $46.3 \%$ were urban residents, whereas $43.8 \%$ of the non- concealing emotions group were urban residents $(p$-value $=0.039)$. Of the concealing emotions group, $48.4 \%$ had low income, 81.4\% had more than a high school education, $98.3 \%$ had national health insurance, $84.4 \%$ had additional private insurance, and $50.1 \%$ had chronic disease, whereas $43.8 \%$ of the non-concealing emotions group had chronic disease ( $p$-value $<0.001$ ).

Regarding medical utilization, $9.7 \%$ of the concealing emotions group and $7.7 \%$ of the non-concealing emotions group had been hospitalized within the last year ( $\mathrm{p}$-value $=0.004), 24.8 \%$ of the concealing emotions group and $22.0 \%$ of the non-concealing emotions group had been outpatients within the last two weeks ( $\mathrm{p}$-value $=0.008$ ), and $28.3 \%$ of concealing emotions group and $25.4 \%$ of the non-concealing emotions group had used pharmaceutical drugs in the last two weeks ( $\mathrm{p}$-value $=0.008$ ).

\section{Medical utilization}

Table 2 presents all differences and significance values between hospitalization groups. 600 participants were hospitalization group, whereas 6,488 participants were non-hospitalization group. The hospitalization group included $9.5 \%$ of females and $7.6 \%$ of males respondents $(p$-value $=0.006), 7.8 \%$ of heavy drinkers, $7.3 \%$ of moderate drinkers and $10.6 \%$ of non-drinkers ( $\mathrm{p}$-value $<0.001$ ), $7.4 \%$ of smokers and $8.9 \%$ of non-smokers ( $p$-value $=0.041$ ), $8.9 \%$ of married people and $6.9 \%$ of non-married people ( $\mathrm{p}$-value $=0.024)$, and $10.2 \%$ of the lowest education group - a higher proportion than the other education groups $(\mathrm{p}$-value $=0.040)$. The hospitalization group also included $9.6 \%$ of those with chronic disease and $7.5 \%$ of those without chronic disease ( $p$-value $=0.002$ ).

Table 2 also presents all differences and significance values for the outpatient visits groups. 1,637 participants were outpatient visits group, whereas 5,454 participants were non-outpatient visits group. The outpatient visits group included $27.6 \%$ of females and $19.2 \%$ of males respondents ( $\mathrm{p}$-value $<0.001$ ), $30.9 \%$ of participants over 50 years old (the highest of all age groups) ( $\mathrm{p}$-value < $0.001), 19.1 \%$ of heavy drinkers, $22.2 \%$ of moderate drinkers and $26.6 \%$ of non-drinkers ( $\mathrm{p}$-value $<0.001$ ), $17.6 \%$ of smokers and $25.6 \%$ of non-smokers ( $\mathrm{p}$-value $<0.001$ ), $22.3 \%$ of paid workers and $24.6 \%$ of self-employees (p-value $=0.038)$, and $30.1 \%$ of the lowest education group-the highest among all education groups ( $\mathrm{p}-$ 
Table 1 Differences between those who concealed or did not conceal their emotions at work

\begin{tabular}{|c|c|c|c|c|}
\hline \multirow{2}{*}{ Variables } & & \multicolumn{3}{|c|}{ Concealing emotions at work $\mathrm{N}(\%)$} \\
\hline & & Yes & No & P-value \\
\hline \multirow[t]{2}{*}{ Gender } & Male & $1454(52.6)$ & $2383(55.0)$ & 0.051 \\
\hline & Female & $1309(47.4)$ & $1948(45.0)$ & \\
\hline \multirow[t]{4}{*}{ Age } & $20 \sim 29$ & $455(16.5)$ & $713(16.5)$ & 0.404 \\
\hline & $30 \sim 39$ & $910(32.9)$ & $1349(31.1)$ & \\
\hline & $40 \sim 49$ & $961(34.8)$ & $1575(36.4)$ & \\
\hline & $50 \sim 54$ & $437(15.8)$ & $694(16.0)$ & \\
\hline \multirow[t]{3}{*}{ Alcohol intake* } & Heavy drinking & $498(18.0)$ & 787 (18.2) & 0.884 \\
\hline & Moderate drinking & $1369(49.6)$ & $2121(49.0)$ & \\
\hline & Non-drinking & $893(32.4)$ & $1420(32.8)$ & \\
\hline \multirow[t]{2}{*}{ Smoking $^{\dagger}$} & Current & $875(31.7)$ & $1346(31.1)$ & 0.612 \\
\hline & Never or past & $1885(68.3)$ & $2982(68.9)$ & \\
\hline \multirow[t]{3}{*}{$\mathrm{BMI}^{\ddagger}$} & Low & $123(4.5)$ & $187(4.4)$ & 0.816 \\
\hline & Normal & $1756(63.9)$ & $2716(63.3)$ & \\
\hline & Obese & 869 (31.6) & 1387 (32.3) & \\
\hline \multirow[t]{2}{*}{ Work type } & Paid worker & $1797(65.1)$ & $2883(66.6)$ & 0.199 \\
\hline & Self-employed & $964(34.9)$ & $1446(33.4)$ & \\
\hline \multirow[t]{2}{*}{ Work schedule } & Shift worker & $616(22.3)$ & $769(17.8)$ & $<0.001$ \\
\hline & Day worker & $2141(77.7)$ & $3552(82.2)$ & \\
\hline \multirow[t]{2}{*}{ Married } & Yes & $2243(81.6)$ & $3491(81.2)$ & 0.700 \\
\hline & No & $507(18.4)$ & $810(18.8)$ & \\
\hline \multirow[t]{2}{*}{ Region } & Urban & $1280(46.3)$ & $1897(43.8)$ & 0.039 \\
\hline & Rural & $1483(53.7)$ & $2434(56.2)$ & \\
\hline \multirow[t]{2}{*}{ Income $e^{\S}$} & High & $1406(51.6)$ & $2224(52.1)$ & 0.675 \\
\hline & Low & $1320(48.4)$ & $2043(47.9)$ & \\
\hline \multirow[t]{3}{*}{ Education" } & Middle school or lower & $513(18.6)$ & $774(17.9)$ & 0.736 \\
\hline & High school & $1167(42.2)$ & $1857(42.9)$ & \\
\hline & College or higher & $1083(39.2)$ & 1699 (39.2) & \\
\hline \multirow[t]{3}{*}{ Public insurance } & National health insurance & $2703(98.2)$ & $4233(98.4)$ & 0.084 \\
\hline & National medical protection & $43(1.6)$ & $68(1.6)$ & \\
\hline & Nothing & $5(0.2)$ & $1(0.0)$ & \\
\hline \multirow[t]{2}{*}{ Additional private insurance } & Yes & $2284(84.4)$ & $3567(84.3)$ & 0.967 \\
\hline & No & $423(15.6)$ & $664(15.7)$ & \\
\hline \multirow[t]{2}{*}{ Chronic Disease } & Yes & $1384(50.1)$ & $1896(43.8)$ & $<0.001$ \\
\hline & No & 1379 (49.9) & $2435(56.2)$ & \\
\hline \multirow[t]{2}{*}{ Hospitalization } & Yes & $267(9.7)$ & $333(7.7)$ & 0.004 \\
\hline & No & $2494(90.3)$ & $3994(92.3)$ & \\
\hline
\end{tabular}


Table 1 Differences between those who concealed or did not conceal their emotions at work (Continued)

\begin{tabular}{|c|c|c|c|c|}
\hline \multirow[t]{2}{*}{ Outpatients visits } & Yes & $684(24.8)$ & $953(22.0)$ & 0.008 \\
\hline & No & 2077 (75.2) & 3377 (78.0) & \\
\hline \multirow[t]{2}{*}{ Pharmaceutical drug use } & Yes & $782(28.3)$ & $1100(25.4)$ & 0.008 \\
\hline & No & 1981 (71.7) & $3230(74.6)$ & \\
\hline
\end{tabular}

${ }^{*}$ Heavy drinkers were those who consumed an average of $\geq 7$ units of alcohol for men and $\geq 5$ units for women $\geq 2$ days/week. Moderate drinkers included those who consumed more than one glass of alcohol per month over the past year, and non-drinkers included those who never drink or drank less than one glass of alcohol per month over the past year.

${ }^{\dagger}$ Current smokers or never/past smokers.

${ }^{\ddagger}$ Body mass index (BMI) was categorized into three groups as low weight $\left(\mathrm{BMl}<18.5 \mathrm{~kg} / \mathrm{m}^{2}\right.$ ), normal weight $\left(\mathrm{BMI} 18.5-25 \mathrm{~kg} / \mathrm{m}^{2}\right)$, and obese $\left(\mathrm{BMI}>25 \mathrm{~kg} / \mathrm{m}^{2}\right)$. ${ }^{5}$ Household income was estimated using the quadrants provided by the KNHANES and relabeled as high and low, which includes the top two an bottom two quadrants, respectively.

"Education was divided among those who only completed middle school or less, those who only graduated from high school or completed some high school, and those who attended college or higher.

value $<0.001)$. This group also included $34.2 \%$ of participants with national medical protection (the highest of all public insurance groups) ( $\mathrm{p}$-value $=0.018$ ), 23.5\% of those with additional private insurance and 20.7\% those without additional private insurance, and 29.8\% of those with chronic disease, but only $17.3 \%$ of those without chronic disease ( $p$-value $<0.001$ ).

Table 2 also presents all differences between pharmaceutical drug use groups, along with significance values. 1,882 participants were pharmaceutical drug use group, whereas 5,211 participants were non-pharmaceutical drug use group. The pharmaceutical drug use group included $31.3 \%$ of females but only $22.5 \%$ of males respondents (p-value $<0.001), 29.9 \%$ of participants over 50 (the highest of all age groups) (p-value $=0.001), 24.0 \%$ of heavy drinkers, $25.8 \%$ of moderate drinkers and $29.1 \%$ of non-drinkers $(\mathrm{p}$-value $=0.001), 22.3 \%$ of smokers and $28.5 \%$ of non-smokers (p-value $<0.001$ ), $28.0 \%$ of participants with a low income but only $25.2 \%$ of those with a high income ( $\mathrm{p}$-value $=0.009$ ), $31.2 \%$ of participants in the lowest education group (the highest of all education groups) (p-value $<0.001$ ), and $32.3 \%$ of those with a chronic disease, but only $21.6 \%$ of those without a chronic disease ( $\mathrm{p}$-value $<0.001$ ).

\section{Association between concealing emotions at work and medical utilization}

All ORs represent the odds of belonging to the concealing emotions group over the non-concealing emotions group. The crude ORs $(95 \% \mathrm{CI})$ were 1.28 (1.09-1.52) for hospitalization, $1.17(1.04-1.31)$ for outpatient visits, and 1.16 (1.04-1.29) for pharmaceutical drug use. In Model I, adjusting for gender, age, alcohol consumption, smoking, and obesity, the adjusted ORs (95\% CI) were 1.30 (1.09-1.54) for hospitalization, 1.17 (1.04-1.31) for outpatient visits, and 1.15 (1.03-1.28) for pharmaceutical drug use. In Model II, further adjusting for employment status, work schedule, marriage, region, income, education, type of public insurance, and additional private insurance, the adjusted ORs (95\% CI) were 1.30 (1.10-1.55) for hospitalization, $1.19(1.06-1.33)$ for outpatient visits, and 1.15 (1.03-1.29) for pharmaceutical drug use. In Model III, further adjusting for individual chronic disease, the adjusted ORs (95\% CI) were 1.29 (1.08-1.53) for hospitalization, 1.15 (1.02-1.29) for outpatient visits, and 1.12 (1.01-1.25) for pharmaceutical drug use.

We then conducted advanced logistic regression models with gender stratification. All odds ratios again represent the odds of belonging to the concealing emotions group over the non-concealing emotions group. For males, the crude ORs (95\% CI) were 1.23 (0.97-1.57) for hospitalization, $1.05(0.89-1.24)$ for outpatient visits, and $1.10(0.94-1.28)$ for pharmaceutical drug use. In Model I, for males, the adjusted ORs (95\% CI) were 1.26 (0.99-1.61) for hospitalization, $1.06(0.89-1.25)$ for outpatient visits, and $1.10(0.94-1.28)$ for pharmaceutical drug use. In Model II, for males, the adjusted ORs (95\% CI) were $1.27(0.99-1.62)$ for hospitalization, 1.07 (0.91-1.27) for outpatient visits, and 1.11 (0.94-1.30) for pharmaceutical drug use. In Model III, for males, the adjusted ORs (95\% CI) were 1.25 (0.98-1.60) for hospitalization, $1.05(0.88-1.24)$ for outpatient visits, and 1.08 (0.92-1.27) for pharmaceutical drug use.

Next, we conducted identical advanced logistic regression models for females. The crude ORs (95\% CI) were 1.33 (1.05-1.68) for hospitalization, 1.26 (1.081.47 ) for outpatient visits, and 1.20 (1.03-1.39) for pharmaceutical drug use. In Model I, for females, the adjusted ORs $(95 \%$ CI) were 1.34 (1.05-1.70) for hospitalization, 1.27 (1.09-1.49) for outpatient visits, and 1.20 (1.03-1.39) for pharmaceutical drug use. In Model II, for females, the adjusted ORs (95\% CI) were 1.32 (1.03-1.69) for hospitalization, 1.30 (1.11-1.53) for outpatient visits, and 1.18 (1.01-1.38) for pharmaceutical drug use. In Model III, for females, the adjusted ORs (95\% CI) were 1.30 (1.02-1.66) for hospitalization, 1.25 (1.06-1.47) for outpatient visits, and 1.14 (0.98-1.33) for pharmaceutical drug use (Table 3). 
Table 2 Variable differences by hospitalization, outpatient visits and pharmaceutical drug use

\begin{tabular}{|c|c|c|c|c|c|c|c|c|c|c|}
\hline \multirow{2}{*}{ Variables } & & \multicolumn{3}{|c|}{ Hospitalization N(\%) } & \multicolumn{3}{|c|}{ Outpatients visits $\mathrm{N}(\%)$} & \multicolumn{3}{|c|}{ Pharmaceutical drug use $\mathrm{N}(\%)$} \\
\hline & & Yes & No & P-value & Yes & No & P-value & Yes & No & P-value \\
\hline \multirow[t]{2}{*}{ Gender } & Male & $292(7.6)$ & $3542(92.4)$ & 0.006 & 737 (19.2) & $3098(80.8)$ & $<0.001$ & $863(22.5)$ & $2973(77.5)$ & $<0.001$ \\
\hline & Female & 308 ( 9.5) & $2946(90.5)$ & & $900(27.6)$ & $2356(72.4)$ & & 1019 (31.3) & $2238(68.7)$ & \\
\hline \multirow[t]{4}{*}{ Age } & $20 \sim 29$ & 107 ( 9.2) & $1061(90.8)$ & 0.090 & $250(21.4)$ & 916 (78.6) & $<0.001$ & $329(28.2)$ & $839(71.8)$ & 0.001 \\
\hline & $30 \sim 39$ & $196(8.7)$ & $2062(91.3)$ & & $439(19.4)$ & $1820(80.6)$ & & $535(23.7)$ & $1724(76.3)$ & \\
\hline & $40 \sim 49$ & 188 ( 7.4) & 2345 (92.6) & & $598(23.6)$ & 1937 (76.4) & & $680(26.8)$ & $1855(73.2)$ & \\
\hline & $50 \sim 54$ & 109 ( 9.7) & $1020(90.3)$ & & $350(30.9)$ & $781(69.1)$ & & $338(29.9)$ & $793(70.1)$ & \\
\hline \multirow[t]{3}{*}{ Alcohol intake } & Heavy drinking & $100(7.8)$ & $1184(92.2)$ & $<0.001$ & $245(19.1)$ & $1040(80.9)$ & $<0.001$ & $308(24.0)$ & $977(76.0)$ & 0.001 \\
\hline & Moderate drinking & 255 ( 7.3$)$ & 3233 (92.7) & & 776 (22.2) & 2712 (77.8) & & 899 (25.8) & $2591(74.2)$ & \\
\hline & Non-drinking & 245 (10.6) & 2065 (89.4) & & $614(26.6)$ & 1698 (73.4) & & $673(29.1)$ & 1639 (70.9) & \\
\hline \multirow[t]{2}{*}{ Smoking $^{\dagger}$} & Current & 165 ( 7.4) & 2054 (92.6) & 0.041 & $390(17.6)$ & 1829 (82.4) & $<0.001$ & $495(22.3)$ & $1726(77.7)$ & $<0.001$ \\
\hline & Never or past & 434 ( 8.9) & 4429 (91.1) & & 1245 (25.6) & 3621 (74.4) & & 1385 (28.5) & 3481 (71.5) & \\
\hline \multirow[t]{3}{*}{$\mathrm{BMI}^{\ddagger}$} & Low & $23(7.4)$ & 287 (92.6) & 0.485 & 74 (23.9) & $236(76.1)$ & 0.082 & $92(29.7)$ & $218(70.3)$ & 0.341 \\
\hline & Normal & 365 ( 8.2) & 4101 (91.8) & & $992(22.2)$ & 3477 (77.8) & & $1171(26.2)$ & $3300(73.8)$ & \\
\hline & Obese & 201 ( 8.9) & 2055 (91.1) & & $555(24.6)$ & $1701(75.4)$ & & $611(27.1)$ & $1645(72.9)$ & \\
\hline \multirow[t]{2}{*}{ Work type } & Paid worker & 386 ( 8.3) & $4292(91.7)$ & 0.381 & 1045 (22.3) & 3635 (77.7) & 0.038 & $1218(26.0)$ & $3462(74.0)$ & 0.174 \\
\hline & Self-employed & 214 ( 8.9) & 2192 (91.1) & & 591 (24.6) & 1816 (75.4) & & 664 (27.6) & 1745 (72.4) & \\
\hline \multirow[t]{2}{*}{ Work schedule } & Shift worker & 116 ( 8.4) & 1268 (91.6) & 0.971 & $300(21.7)$ & $1083(78.3)$ & 0.174 & $361(26.1)$ & $1023(73.9)$ & 0.686 \\
\hline & Day worker & $481(8.5)$ & 5207 (91.5) & & 1335 (23.5) & 4357 (76.5) & & 1518 (26.7) & 4175 (73.3) & \\
\hline \multirow[t]{2}{*}{ Married } & Yes & 509 ( 8.9) & $5220(91.1)$ & 0.024 & 1349 (23.5) & $4383(76.5)$ & 0.058 & 1507 (26.3) & $4226(73.7)$ & 0.362 \\
\hline & No & $91(6.9)$ & $1225(93.1)$ & & $277(21.0)$ & 1039 (79.0) & & 363 (27.6) & $954(72.4)$ & \\
\hline \multirow[t]{2}{*}{ Region } & Urban & $250(7.9)$ & $2925(92.1)$ & 0.117 & 737 (23.2) & $2440(76.8)$ & 0.862 & $876(27.6)$ & $2300(72.4)$ & 0.076 \\
\hline & Rural & $350(8.9)$ & $3563(91.1)$ & & $900(23.0)$ & $3014(77.0)$ & & $1006(25.7)$ & $2911(74.3)$ & \\
\hline \multirow[t]{2}{*}{ Income $e^{\S}$} & High & $317(8.7)$ & $3310(91.3)$ & 0.513 & $842(23.2)$ & $2788(76.8)$ & 0.990 & $916(25.2)$ & $2714(74.8)$ & 0.009 \\
\hline & Low & $278(8.3)$ & $3082(91.7)$ & & $778(23.2)$ & $2582(76.8)$ & & $942(28.0)$ & $2420(72.0)$ & \\
\hline \multirow[t]{3}{*}{ Education" } & Middle school or lower & $131(10.2)$ & 1154 (89.8) & 0.040 & $388(30.1)$ & $899(69.9)$ & $<0.001$ & $402(31.2)$ & $885(68.8)$ & $<0.001$ \\
\hline & High school & $238(7.9)$ & $2783(92.1)$ & & $645(21.3)$ & $2377(78.7)$ & & $790(26.1)$ & $2233(73.9)$ & \\
\hline & College or higher & $230(8.3)$ & $2551(91.7)$ & & $604(21.7)$ & 2177 (78.3) & & $690(24.8)$ & $2092(75.2)$ & \\
\hline \multirow[t]{3}{*}{ Public insurance } & National health insurance & $589(8.5)$ & $6341(91.5)$ & 0.658 & 1587 (22.9) & $5346(77.1)$ & 0.018 & $1830(26.4)$ & $5105(73.6)$ & 0.111 \\
\hline & National medical protection & 11 ( 9.9) & $100(90.1)$ & & $38(34.2)$ & $73(65.8)$ & & $37(33.3)$ & $74(66.7)$ & \\
\hline & Nothing & $0(0.0)$ & $6(100.0)$ & & $1(16.7)$ & $5(83.3)$ & & $3(50.0)$ & $3(50.0)$ & \\
\hline
\end{tabular}


Table 2 Variable differences by hospitalization, outpatient visits and pharmaceutical drug use (Continued)

\begin{tabular}{|c|c|c|c|c|c|c|c|c|c|c|}
\hline \multirow[t]{2}{*}{ Additional private insurance } & Yes & $511(8.7)$ & 5335 (91.3) & 0.153 & $1376(23.5)$ & $4474(76.5)$ & 0.048 & $1566(26.8)$ & $4284(73.2)$ & 0.399 \\
\hline & No & $80(7.4)$ & $1006(92.6)$ & & $225(20.7)$ & $861(79.3)$ & & $277(25.5)$ & $810(74.5)$ & \\
\hline \multirow[t]{2}{*}{ Chronic disease } & Yes & $314(9.6)$ & $2962(90.4)$ & 0.002 & $976(29.8)$ & $2303(70.2)$ & $<0.001$ & $1060(32.3)$ & $2219(67.7)$ & $<0.001$ \\
\hline & No & $286(7.5)$ & 3526 (92.5) & & 661 (17.3) & 3151 (82.7) & & $822(21.6)$ & 2992 (78.4) & \\
\hline
\end{tabular}

"Heavy drinkers were those who consumed an average of $\geq 7$ units of alcohol for men and $\geq 5$ units for women $\geq 2$ days/week. Moderate drinkers included those who consumed more than one glass of alcohol per month over the past year, and non-drinkers included those who never drink or drank less than one glass of alcohol per month over the past year.

${ }^{\dagger}$ Current smokers or never/past smokers.

${ }^{\ddagger}$ Body mass index (BMI) was categorized into three groups as low weight $\left(\mathrm{BMI}<18.5 \mathrm{~kg} / \mathrm{m}^{2}\right)$, normal weight $\left(\mathrm{BMI} 18.5-25 \mathrm{~kg} / \mathrm{m}^{2}\right)$, and obese $\left(\mathrm{BMI}>25 \mathrm{~kg} / \mathrm{m}^{2}\right)$.

${ }^{5}$ Household income was estimated using the quadrants provided by the KNHANES and relabeled as high and low, which includes the top two an bottom two quadrants, respectively.

"Education was divided among those who only completed middle school or less, those who only graduated from high school or completed some high school, and those who attended college or higher. 
Table 3 Results of the logistic regression analyses

\begin{tabular}{lllll}
\hline Variables & Crude & Model I & Model II $^{\dagger}$ & Model III $^{\ddagger}$ \\
\hline Total population & & & & \\
$\quad$ Hospitalization & $1.28(1.09 \sim 1.52)$ & $1.30(1.09 \sim 1.54)$ & $1.30(1.10 \sim 1.55)$ & $1.29(1.08 \sim 1.53)$ \\
$\quad$ Outpatients visits & $1.17(1.04 \sim 1.31)$ & $1.17(1.04 \sim 1.31)$ & $1.19(1.06 \sim 1.33)$ & $1.15(1.02 \sim 1.29)$ \\
$\quad$ Pharmaceutical drug use & $1.16(1.04 \sim 1.29)$ & $1.15(1.03 \sim 1.28)$ & $1.15(1.03 \sim 1.29)$ & $1.12(1.01 \sim 1.25)$ \\
Males & & & & $1.25(0.98 \sim 1.60)$ \\
$\quad$ Hospitalization & $1.23(0.97 \sim 1.57)$ & $1.26(0.99 \sim 1.61)$ & $1.27(0.99 \sim 1.62)$ & $1.05(0.88 \sim 1.24)$ \\
$\quad$ Outpatients visits & $1.05(0.89 \sim 1.24)$ & $1.06(0.89 \sim 1.25)$ & $1.07(0.91 \sim 1.27)$ & $1.08(0.92 \sim 1.27)$ \\
$\quad$ Pharmaceutical drug use & $1.10(0.94 \sim 1.28)$ & $1.10(0.94 \sim 1.28)$ & $1.11(0.94 \sim 1.30)$ & \\
Females & & & & $1.32(1.03 \sim 1.69)$ \\
$\quad$ Hospitalization & $1.33(1.05 \sim 1.68)$ & $1.34(1.05 \sim 1.70)$ & $1.30(1.11 \sim 1.53)$ & $1.25(1.06 \sim 1.47)$ \\
$\quad$ Outpatients visits & $1.26(1.08 \sim 1.47)$ & $1.27(1.09 \sim 1.49)$ & $1.18(1.01 \sim 1.38)$ & $1.14(0.98 \sim 1.33)$ \\
$\quad$ Pharmaceutical drug use & $1.20(1.03 \sim 1.39)$ & $1.20(1.03 \sim 1.39)$ & $1.66)$ \\
\hline
\end{tabular}

"Model I: Adjusted for individual factors (gender, age, alcohol intake, smoking, BMI).

${ }^{\dagger}$ Model II: Model I + Adjusted for occupational factors (employment status, work schedule) and socioeconomic factors (marriage, region, income, education, type of public insurance, additional private insurance).

${ }^{\ddagger}$ Model III: Model II + Adjusted for individual disease factor (chronic disease).

\section{Discussion}

Our current study shows that the concealing emotions group had a higher rate of hospitalization, outpatient visits, and pharmaceutical drug use. This finding was consistent across all models before gender stratification. This finding suggests that concealing emotions is detrimental for health as measured by increased medical utilization. Concealing emotions is a kind of occupational stress, which is associated with many acute and chronic diseases $[1,5]$. Moreover, occupational stress is related to depression which is closely related to many other acute and chronic diseases [21,22]. Concealing emotions group has a higher rate of medical utilization due to these reasons. For males, compared to the non-concealing emotions group, the concealing emotions group had a higher rate of hospitalization, outpatient visits, and pharmaceutical drug use, but this result was non-significant across all models. Conversely, in females, the concealing emotions group has higher rates of hospitalization, outpatient visits, and pharmaceutical drug use. All adjusted models, except Model III, were statistically significant. Therefore, concealing emotions at work might be more detrimental for women than it is for men, especially since gender is an important factor in determining medical utilization [8-10]. Furthermore, concealing emotions at work might causes more occupational stress among females than males [23,24]. Previous studies have reported that females experience more stress than males do because of differences in perception, exposure to work, physical capacity, and burdens having to do with their household [25-29].

The concealing emotions group had a greater proportion of shift workers than the non-concealing group. Shift workers tend to work as call center operators, health care providers, and nurses, all of whom require concealing emotions by the nature of their work [30]. Because both concealing emotions and shift work are detrimental to health, the implications of these two factors is of concern [15]. The concealing emotions group also tended to be urban residents to a greater extent than the non-concealing emotions group. This finding might suggest that concealing emotions is required in office jobs, which is predominant in urban environments. The concealing emotions group also had a higher rate of chronic disease, hospitalization, outpatient visits, and pharmaceutical drug use, suggesting that concealing emotions at work is harmful to health. This finding supports the finding that concealing emotions is harmful to health in general [2]. This might have resulted because emotional experiences have been found to affect physiologic health such as the immune system [31].

According to all medical utilization indexes, females tend to access medical services more than males, suggesting that females are more active in medical utilization, which has been supported by previous studies [8-10]. Since healthy individuals are more likely to drink alcohol and smoke cigarettes (Similar to sick person effects) [32], and Korean males drink and smoke more often than females [33,34], in contrary to our expectations, alcohol drinkers and cigarette smokers in our study used medical services less than those who did not drink alcohol or smoke cigarettes. The rate of self-employment among those who visited an outpatient clinic was higher than that among paid workers. One possible explanation for this result is that clinic operating hours and working hours overlap. In low income group, the rate of pharmaceutical drug use was higher than those in high income group was probably due to their limited access to hospitalization and 
outpatients visits. However, this result is not consistent with previous research [35]. The lowest education group in our study used more medical services since older people had lower education than younger people in Korea and this result was also supported by previous studies $[36,37]$. The national medical protection group and having private insurance group visited the outpatient clinic more frequently than other groups, and this could be induced by moral hazard $[18,19,38]$.

Emotional labor is defined as work in which emotional demands are inherent. Employees are expected to express certain emotions to customers to meet the demands of their job and they can be reprimanded when they do not meet the emotional demands [39]. Emotional labor is one component of job stress [40] and is related to various chronic diseases such as cardiovascular disease [2]. Concealing emotions at work is a crucial component of emotional labor. Thus, in accordance with our findings, we cautiously suggest that female workers in fields that require emotional concealment tend to use more medical services. Currently, emotional labor is a controversial issue in Korean labor policy. Workers have been forced to conceal their emotions at work. However, few policies exist that protect workers who have to conceal their emotions at work. Moreover, few studies have investigated the health effects of concealing emotions at work in Korea. We hope that this study will play the role of cornerstone in the establishment of future labor policies in Korea that deal with concealing emotions at work.

Our study had some clear strengths. First, we included a large sample size with more than 7,000 participants. Second, we investigated the association between concealing emotions at work and medical utilization with and without gender stratification. Third, potential confounders such as individual factors (model I), occupation and socioeconomic factors (model II), and individual diseases factor (model III) were adjusted for in our statistical analyses. Confounder adjustment increased the level of C-values and reduced the level of Akaike Information Criterion (AIC). For example, C-value increased from 0.534 to 0.623 and AIC decreased from 2037 to 1908 for hospitalization among females. Fourth, to the best of our knowledge, this was the first study investigating the association between concealing emotions at work and medical utilization.

Our study also had some limitations. First, the main independent variable-concealing emotions at work - was based on a subjective answer to only one questionnaire item. Thus, we were not able to objectively determine whether participants did or did not conceal their emotions at work, which might lead to a non-differential misclassification and underestimation. Second, medical utilization was measured using a subjective questionnaire. Many other methods for acquiring information on medical utilization exist, such as checking insurance data and checking hospital data. In some cases, information obtained by self-report methods does not correspond with information obtained by checking insurance data or hospital data due to potential biases, such as recall bias. However, in Korea, insurance and hospital data are protected by Korean law. Thus, self-report is considered the next best method and has been used in many studies $[41,42]$. Nevertheless, we believe that our large sample size might have outweighed the potential benefits of using a different method of data collection. Third, the calculated $\mathrm{C}$-values of our models were low $(0.580 \sim 0.629)$. Thus, our logistic regression models might not have been able to provide enough explanation for the influence of concealing emotions on medical utilization. Further studies are needed.

In summary, we found that those who concealed emotions at work were more likely to use medical services, with higher rates of hospitalization, outpatient visits, and pharmaceutical drug use than those who did not conceal emotions were. When we stratified the data by gender, no statistical significance among males was found, but a significant difference was found among females. Thus, the health effects of concealing emotions at work might be more detrimental for women than it is for men. We anticipate that our study, with over 7,000 participants, provides important insights into the health consequences of concealing emotions at work.

\section{Competing interests}

The authors declare that they have no competing interests.

\section{Authors' contributions}

HS: The first author of this article. He designed the study, collected and interpreted the data, and drafted the manuscript. JHY: He suggested the study design, interpreted the data, and revised the manuscript. WL: He suggested the study design, interpreted the data, and revised the manuscript. JHL: He collected the data and drafted the manuscript. PKJ: He collected the data and drafted the manuscript. IK: She suggested the study design, interpreted the data, and revised the manuscript. JUW: He suggested the study design, interpreted the data, and revised the manuscript. JR: The corresponding author of this article. He suggested the study design, interpreted the data, and revised the manuscript. All authors have approved the final version of the manuscript.

\section{Author details}

${ }^{1}$ Graduate School of Public Health, Yonsei University, Seoul, Korea. ${ }^{2}$ The Institute for Occupational Health, Yonsei University College of Medicine, Seoul, Korea. ${ }^{3}$ Department of Preventive Medicine and Public Health, Yonsei University College of Medicine, Seoul, Korea.

Received: 31 March 2014 Accepted: 17 September 2014

Published online: 01 October 2014

\section{References}

1. Cheng C, Bartram T, Karimi L, Leggat SG: The role of team climate in the management of emotional labour: implications for nurse retention. $J$ Adv Nurs 2013, 69(12):2812-2825.

2. Chapman BP, Fiscella K, Kawachi I, Duberstein P, Muennig P: Emotion suppression and mortality risk over a 12-year follow-up. J Psychosom Res 2013, 75(4):381-385

3. Myers LB, Vetere A, Derakshan N: Are suppression and repressive coping related? Pers Indiv Differ 2004, 36(5):1009-1013. 
4. de Castro AB, Agnew J, Fitzgerald ST: Emotional labor: relevant theory for occupational health practice in post-industrial America. AAOHN J 2004, 52(3):109-115

5. De Bacquer D, Pelfrene E, Clays E, Mak R, Moreau M, de Smet P, Kornitzer M, De Backer G: Perceived job stress and incidence of coronary events: 3-year follow-up of the Belgian Job Stress Project cohort. Am J Epidemiol 2005, 161(5):434-441.

6. Slany C, Schutte S, Chastang JF, Parent-Thirion A, Vermeylen G, Niedhammer I: Psychosocial work factors and long sickness absence in Europe. Int J Occup Environ Health 2014, 20(1):16-25.

7. Goetzel RZ, Gibson TB, Short ME, Chu BC, Waddell J, Bowen J, Lemon SC, Fernandez ID, Ozminkowski RJ, Wilson MG, DeJoy DM: A multi-worksite analysis of the relationships among body mass index, medical utilization, and worker productivity. J Occup Environ Med 2010, 52(Suppl 1):S52-S58.

8. Vikum E, Krokstad S, Westin S: Socioeconomic inequalities in health care utilisation in Norway: the population-based HUNT3 survey. Int J Equity Health 2012, 11:48

9. Cameron KA, Song J, Manheim LM, Dunlop DD: Gender disparities in health and healthcare use among older adults. J Women's Health 2010, 19(9):1643-1650.

10. Dunlop DD, Manheim LM, Song J, Chang RW: Gender and ethnic/racial disparities in health care utilization among older adults. J Geronto/ Ser B Psychol Sci Soc Sci 2002, 57(4):S221-S233.

11. Vals K, Kiivet RA, Leinsalu M: Alcohol consumption, smoking and overweight as a burden for health care services utilization: a cross-sectional study in Estonia. BMC Public Health 2013, 13:772.

12. Risal A, Tharoor $\mathrm{H}$ : A cross-sectional comparison of drinking patterns, alcohol use and related medical morbidities in a secondary versus tertiary setting. Kathmandu Univ Med J (KUMJ) 2013, 11(42):152-157.

13. Quesenberry CP Jr, Caan B, Jacobson A: Obesity, health services use, and health care costs among members of a health maintenance organization. Arch Intern Med 1998, 158(5):466-472.

14. Meer J, Rosen HS: Insurance and the utilization of medical services. Soc Sci Med 2004, 58(9):1623-1632

15. Bambra CL, Whitehead MM, Sowden AJ, Akers J, Petticrew MP: Shifting schedules: the health effects of reorganizing shift work. Am J Prev Med 2008, 34(5):427-434.

16. Krumkamp R, Sarpong N, Kreuels B, Ehlkes L, Loag W, Schwarz NG, Zeeb H, Adu-Sarkodie Y, May J: Health care utilization and symptom severity in Ghanaian children-a cross-sectional study. PLoS One 2013, 8(11):e80598.

17. Jerant A, Fiscella K, Tancredi DJ, Franks P: Health insurance is associated with preventive care but not personal health behaviors. J Am Board Fam Med 2013, 26(6):759-767.

18. Jeon B, Kwon S: Effect of private health insurance on health care utilization in a universal public insurance system: a case of South Korea. Health Policy 2013, 113(1-2):69-76.

19. Kang S, You CH, Kwon YD, Oh EH: Effects of supplementary private health insurance on physician visits in Korea. J Formos Med Assoc 2009, 108(12):912-920.

20. Jin-Ha Yoon K-HL, Kyu-Yeon H, Sei Jin C, Bong Suk C, Seong Ho M, Kyung Suk Lee H-SC, Aeyong E, Sang Baek K: Suicide trend of standardized mortality ratio and Age standardized proportion mortality ratio according to occupational groups in Korea: 1993-2007. Korean J Occup Environ Med 2011, 23(2):173-182

21. Deguchi $Y$, Inoue K, Muramatsu T, Iwasaki S, Yamauchi T, Nakao T, Muroya M, Kobayashi Y, Kato Y, Kiriike N: Relationships between occupational stress and depressive symptoms among prison officers in Japan. Osaka City Med J 2013, 59(2):91-98.

22. Egede LE: Depression: greater effect on overall health than angina, arthritis, asthma or diabetes. Evid Based Ment Health 2008, 11(2):57.

23. Johnson HA, Spector PE: Service with a smile: do emotional intelligence, gender, and autonomy moderate the emotional labor process? J Occup Health Psychol 2007, 12(4):319-333.

24. Yu SF, Gu GZ, Zhou WH, Zhou SY, Yang XF, Sun SY: Gender difference of relationship between occupational stress and depressive symptoms. Zhonghua Lao Dong Wei Sheng Zhi Ye Bing Za Zhi 2011, 29(12):887-892.

25. Herrero SG, Saldana MA, Rodriguez JG, Ritzel DO: Influence of task demands on occupational stress: gender differences. J Saf Res 2012, 43(5-6):365-374.
26. Hooftman WE, van der Beek AJ, Bongers PM, van Mechelen W: Gender differences in self-reported physical and psychosocial exposures in jobs with both female and male workers. J Occup Environ Med 2005, 47(3):244-252

27. Nordander C, Ohlsson K, Balogh I, Hansson GA, Axmon A, Persson R, Skerfving S: Gender differences in workers with identical repetitive industrial tasks: exposure and musculoskeletal disorders. Int Arch Occup Environ Health 2008, 81(8):939-947.

28. Matthews S, Hertzman C, Ostry A, Power C: Gender, work roles and psychosocial work characteristics as determinants of health. Soc Sci Med 1998, 46(11):1417-1424.

29. Sekine M, Chandola T, Martikainen P, Marmot M, Kagamimori S: Sex differences in physical and mental functioning of Japanese civil servants: explanations from work and family characteristics. Soc Sci Med 2010, 71(12):2091-2099.

30. Bagdasarov Z, Connelly S: Emotional labor among healthcare professionals: the effects are undeniable. Narrative Inq Bioeth 2013, 3(2):125-129.

31. Salovey P, Rothman AJ, Detweiler JB, Steward WT: Emotional states and physical health. Am Psychol 2000, 55(1):110-121.

32. Sterling TD, Weinkam JJ, Weinkam JL: The sick person effect. J Clin Epidemiol 1990, 43(2):141-151.

33. Service. KKSI: The drinking alcohol rate in Korea. Available: http://kosis.kr/ups3/service/ch file down.jsp?PUBCODE=KP\&FILE NAME=\% 2Fups3\%2Fupload\%2F101\%2FKP0207.xIs\&SEQ=3080\&_ORG_ID=101 [cited 6 Oct 2014].

34. Service. KKSI: The smoking rate in Korea. Available: http://kosis.kr/ups3/service/ch file down.jsp?PUBCODE=KP\&FILE NAME=\% 2Fups3\%2Fupload\%2F101\%2FKP0207.xIs\&SEQ=3080\&_ORG_ID=101 [cited 6 Oct 2014].

35. Lipworth L, Mumma MT, Cavanaugh KL, Edwards TL, Ikizler TA, Tarone RE, McLaughlin JK, Blot WJ: Incidence and predictors of end stage renal disease among low-income blacks and whites. PLoS One 2012, 7(10):e48407.

36. Van der Heyden JH, Demarest S, Tafforeau J, Van Oyen H: Socio-economic differences in the utilisation of health services in Belgium. Health Policy 2003, 65(2):153-165.

37. Service. KKSI: Social indicators in Korea. 2012, Available: http://kosis.kr/ ups3/service/ch_file_down.jsp?PUBCODE=KP\&FILE_NAME=\%2Fups $3 \%$ 2Fupload\%2F101\%2FKP0410.xIs\&SEQ=3126\&_ORGID=101 [cited 6 Oct 2014].

38. Kiil $\mathrm{A}$ : What characterises the privately insured in universal health care systems? A review of the empirical evidence. Health Policy 2012, 106(1):60-75.

39. Brotheridge CM, Grandey AA: Emotional labor and burnout: comparing two perspectives of "people work". J Vocat Behav 2002, 60(1):17-39.

40. Katayama $\mathrm{H}$ : Relationship between emotional labor and job-related stress among hospital nurses. Nippon Eiseigaku Zasshi 2010, 65(4):524-529.

41. Reichert AR, Augurzky B, Tauchmann H: Self-perceived job insecurity and the demand for medical rehabilitation: does fear of unemployment reduce health care utilization? Health Econ 2013, doi10.1002/hec.2995.

42. Peersman W, Pasteels I, Cambier D, De Maeseneer J, Willems S: Validity of self-reported utilization of physician services: a population study. Eur J Pub Health 2014, 24(1):91-97.

doi:10.1186/s40557-014-0031-2

Cite this article as: Seok et al:: The association between concealing emotions at work and medical utilization in Korea. Annals of Occupational and Environmental Medicine 2014 26:31.

\section{Submit your next manuscript to BioMed Central and take full advantage of:}

- Convenient online submission

- Thorough peer review

- No space constraints or color figure charges

- Immediate publication on acceptance

- Inclusion in PubMed, CAS, Scopus and Google Scholar

- Research which is freely available for redistribution 